\title{
A pervasive and persistent Asian dust event over North America during spring 2010: lidar and sunphotometer observations
}

\author{
P. Cottle ${ }^{1}$, K. Strawbridge ${ }^{2}$, I. McKendry ${ }^{3}$, N. O'Neill ${ }^{4}$, and A. Saha ${ }^{4}$ \\ ${ }^{1}$ Department of Earth, Ocean and Atmospheric Sciences, the University of British Columbia, Vancouver, BC, Canada \\ ${ }^{2}$ Air Quality Processes Research Section, Environment Canada, Toronto, ON, Canada \\ ${ }^{3}$ Department of Geography, the University of British Columbia, Vancouver, BC, Canada \\ ${ }^{4}$ Centre d'applications et de recherches en télédétection, Université de Sherbrooke, Sherbrooke, QC, Canada
}

Correspondence to: P. Cottle (pwcottle@gmail.com)

Received: 8 November 2012 - Published in Atmos. Chem. Phys. Discuss.: 27 November 2012

Revised: 25 March 2013 - Accepted: 9 April 2013 - Published: 2 May 2013

\begin{abstract}
Among the many well-documented cases of springtime trans-Pacific transport of crustal dust from Asia to North America (significant events include those of 1998, 2001, and 2005), the events of March and April 2010 were extraordinary both in the extent of the dust distribution and in the unique meteorological conditions that caused the dust layers in the free troposphere to linger and be detectable across Canada and the northern United States for over a month. This study focuses on extending previous research by combining data from CORALNet (Canadian Operational Research Aerosol Lidar Network) lidars in Vancouver, BC, and Egbert, ON, with AERONET (AErosol RObotic NETwork) sunphotometer retrievals and model results from HYSPLIT (HYbrid Single-Particle Lagrangian Integrated Trajectory) and NAAPS (Navy Aerosol Analysis and Prediction System) to monitor the arrival and distribution of dust layers across North America. This is the first documented instance of lidar detection of Asian dust from the Egbert CORALNet installation, where layers identified as dust using depolarization ratios corresponded with retrievals of coarse-mode optical depth at the co-located AEROCAN/AERONET site. In Vancouver dust layer depolarization ratios varied from 0.27 for dust above $6 \mathrm{~km}$ to less than 0.10 for the first $1.5-2 \mathrm{~km}$ above the surface. Similar layers of elevated dust exhibited much lower volume depolarization ratios for all altitudes in Egbert, ON, where maximum depolarization ratios stayed below 0.15 for all layers from $2-8 \mathrm{~km}$ with no clear variation with altitude, or over time. The relative lack of variation is an indication that as the layers of dust were transported across North America the rates of change in their optical proper-
\end{abstract}

ties slowed. HYSPLIT back trajectories performed throughout the free troposphere above these sites showed a majority of air parcels originating from central Asia on the days in question. Using these techniques, it was shown that elevated layers of aerosol reaching the west coast of North America as early as 17 March also included dust from the same central Asian sources, extending the known duration of the 2010 event by almost a full month.

\section{Introduction}

Springtime trans-Pacific transport of crustal dust from the deserts of central Asia to North America has been well documented over the past decade. Noteworthy studies include comprehensive analyses of the significant 1998 (Husar et al., 2001) and 2001 events (Thulasiraman et al., 2002), summaries of multiple events (Fischer et al., 2009; McKendry et al., 2008; Kim et al., 2007), model-based climatologies of trans-Pacific transport processes (e.g. Gong et al., 2006; Stohl et al., 2002), and assessments of impacts of Asian dust on North American air quality (Chin et al., 2007; Jaffe et al., 2003; Zhao et al., 2008; Fairlie et al., 2007; Heald et al., 2006). Thanks to years of continuous data collection by multiple, overlapping global and regional networks of aerosolmonitoring stations, what was once considered to be a relatively rare occurrence is now known to be a regular annual event.

Recently, attention has been drawn to the extraordinary dust transport events of spring 2010. Details of the temporal 


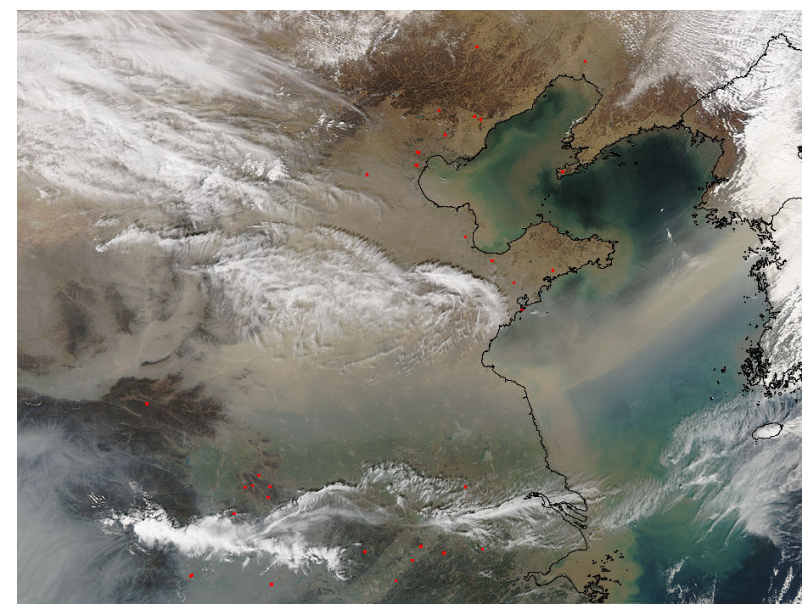

Fig. 1. True-colour image from 12 March 2010 showing dust layers sweeping out over the East China Sea. Image from MODIS instrument on NASA's AQUA satellite is thanks to Jeff Schmaltz and the MODIS Land Rapid Response Team, NASA GSFC.

sequence of dust mobilization in the source regions of China and the meteorological pathways and processes of transPacific transport of the Asian dust during April 2010 are described by Uno et al. (2011). In summary, at least eight major dust mobilization events were shown to have occurred in the Taklamakan and Gobi desert regions between 1 March and 30 April 2010. Of these, the third, fifth, and seventh April events were the largest and all of the events were observed to result in transport of dust to North America. Dust was observed to travel in multiple layers with elevations from 2$10 \mathrm{~km}$ and was observed to split into two distinct pathways. Of particular note in the context of this study is dust following the northern pathway across Canada. A slow moving anticyclone over the central continent during the period 15-22 April resulted in significant subsidence and stagnation, temporarily trapping the dust over the north-eastern portion of the continent. These observations are consistent with observations from Mt. Bachelor Observatory in Oregon, showing increased aerosol loading on 10 April and 19 April corresponding to layers identified as dust or polluted dust by concurrent CALIPSO overpasses (Fischer et al., 2011). While Uno et al. (2011) documented the transport of dust from the largest events of April, plumes have been observed arriving on the west coast of North America in late March as well. These are clearly the result of smaller but still substantial March dust storms documented by Uno et al. (2011) and Li et al. (2012) (MODIS true-colour imagery of one such storm is shown in Fig. 1). With the exception of Fischer et al. (2011), the presence of Asian dust in North America during March 2010 is not well documented.

This study extends and complements the satellite- and global-model-based analyses of Uno et al. (2011), Li et al. (2012) and Fischer et al. (2011) and focuses specifically on ground-based lidar and sunphotometer observations of the

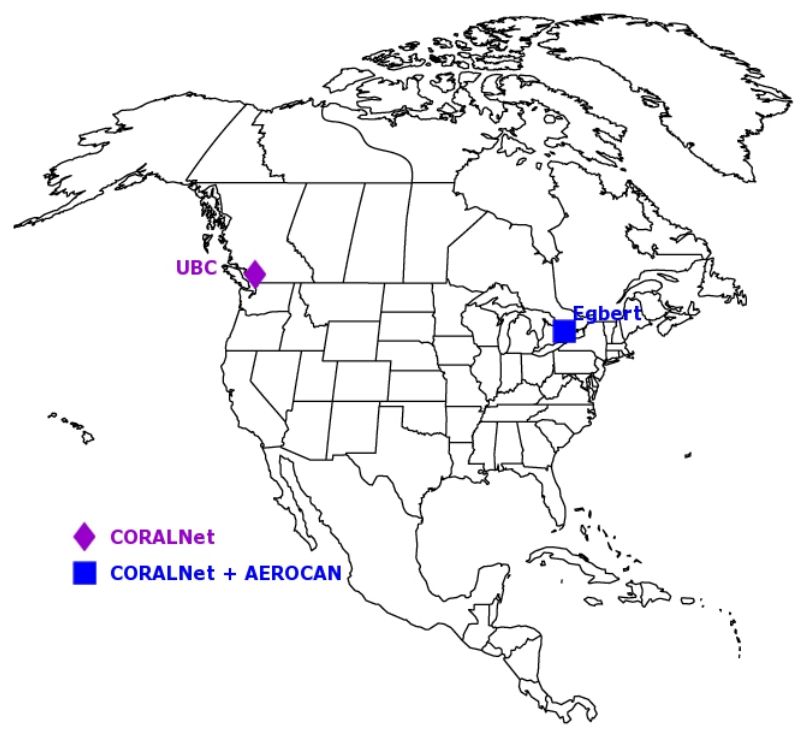

Fig. 2. Map of North America showing locations of CORALNet and AEROCAN stations used in this study.

aerosol layers as they passed over the continent. Lidar observations were collected from CORALnet (Canadian Operational Research Aerosol Lidar Network) stations located in Vancouver, BC, and in Egbert, ON (see Fig. 2). Detailed analysis was performed on SDA (spectral deconvolution algorithm) data from the AEROCAN site in Egbert, co-located with the CORALNet lidar there. Collected data were analysed in combination with results from the NAAPS (Navy Aerosol Analysis and Prediction System) and HYSPLIT (HYbrid Single-Particle Lagrangian Integrated Trajectory) models to provide a more complete picture of the scope and distribution of this event throughout North America, including documentation of additional dust transport events reaching the west coast as early as 17 March.

\section{Methodology}

\subsection{CORALNet}

CORALNet is a semi-autonomous network of ground-based lidars. These remotely controlled facilities are housed in cargo trailers with modifications including a roof hatch assembly, basic meteorological tower, radar interlock system, climate control system and levelling stabilizers. The units can be operated via an internet link and require an external power source. A precipitation sensor is used to operate the roof hatch and three pan/tilt webcams capture sky conditions and monitor the lidar system's health. A remote control interface is used to control all vital components of the system, including the ability to provide hard resets of the laser electronics. 
A Continuum Inlite III (small footprint) laser operating at $1064 / 532 \mathrm{~nm}$ simultaneously with a pulse repetition rate of $10 \mathrm{~Hz}$ is the foundation of the system. The energy output is approximately $150 \mathrm{~mJ}$ at $1064 \mathrm{~nm}$ and no more than $150 \mathrm{~mJ}$ at $532 \mathrm{~nm}$. The upward-pointing system measures the return signal in three channels ( $1064 \mathrm{~nm}$, and two polarization channels at $532 \mathrm{~nm}$ ). Backscatter information is collected at $3 \mathrm{~m}$ vertical resolution with $10 \mathrm{~s}$ averaging over a usable range from near ground to $18 \mathrm{~km}$. Signal correction procedures for each channel include subtraction of background signal from dark current and stray light, application of an overlap correction curve, and an iterative calibration process. Full details of the CORALNet system, including calibration procedures, determination of overlap function, and data product descriptions, can be found in Strawbridge (2013).

Data reported here from the CORALNet lidars include backscatter ratios and linear volume depolarization ratios. In brief, the signal measured by a zenith-pointing lidar for a given wavelength channel, after calibration and background subtraction, can be represented by the lidar equation

$P(z)=E_{0} \frac{c \tau}{2} \frac{A}{z^{2}} \eta\left(\beta_{\mathrm{p}}(z)+\beta_{\mathrm{m}}(z)\right) \exp \left[-2 \int_{0}^{z} \alpha\left(z^{\prime}\right) \mathrm{d} z^{\prime}\right]$,

where $z=$ altitude in AGL units, $P(z)=$ background subtracted signal measured at the detector, $E_{0}=$ average laser pulse output, $c=$ speed of light, $\tau=$ laser pulse duaration, $A=$ usable area of receiver entrance pupil, $\eta=$ overall system efficiency constant, $\beta_{\mathrm{p}}=$ volume backscatter coefficient from particulates, $\beta_{\mathrm{m}}=$ volume backscatter coefficient from molecular (Rayleigh) scattering, and $\alpha=$ volume extinction coefficient.

Using Eq. (1) as a basis, the backscatter ratio $(\gamma(z))$ is defined as the ratio of the total measured backscatter for a given altitude to the signal expected from purely molecular scattering:

$\gamma(z)=\frac{P(z)}{P_{\mathrm{m}}(z)}=\frac{\left(\beta_{\mathrm{p}}(z)+\beta_{\mathrm{m}}(z)\right)}{\beta_{\mathrm{m}}(z)}$,

where

$P_{\mathrm{m}}(z)=E_{0} \frac{c \tau}{2} \frac{A}{z^{2}} \beta_{\mathrm{m}}(z) \exp \left[-2 \int_{0}^{z} \alpha\left(z^{\prime}\right) \mathrm{d} z^{\prime}\right]$.

The linear volume depolarization ratio $(\delta)$ is calculated as the linear ratio of the calibrated attenuated backscatter of the two polarization channels:

$\delta(z)=\xi \frac{P_{\perp}(z)}{P_{\|}(z)}$.

The correction factor $\xi$ is used to correct for differences in throughput and detector sensitivity for the two channels. The procedure for determining this correction is described in
Strawbridge (2013). The volume depolarization ratio represents the average depolarization of all the particles and gases within the measurement volume, not just the particles. It is used because calculating the particle depolarization ratio requires foreknowledge of the ratio between extinction and backscatter (so-called lidar ratio) for each intervening layer. In situations such as this with multiple overlapping layers of various indeterminate levels of mixing between two or more aerosol species, the authors felt the volume depolarization ratio to be the most accurate tool for analysis of the layers.

Even after calibration and background correction, the calculation of stable depolarization ratios from lidar data involving two or more detector channels is often difficult to achieve for high altitudes and areas of low aerosol optical depth. This is due primarily to the fact that in these regions the strength of the lidar signal is small compared to the background noise floor of the detectors, especially for the depolarized channel, resulting in a ratio that is highly unstable. Newer iterations of CORALNet lidar stations address this issue with the use of photon-counting detectors that produce more linear results for low signals, but for the stations in question at the time of this event purely analogue devices were used. Areas of low aerosol optical depth can be identified by a calibrated backscatter ratio near unity. In order to avoid reporting spurious or misleading depolarization ratios, a mask was generated for these regions using the backscatter ratio from the $1064 \mathrm{~nm}$ channel, which provided the cleanest signal. This mask was then applied to the depolarization ratio maps and regions for which the aerosol optical depth was insufficient to calculate a reliable depolarization ratio were masked out. These are regions for which the system is not sensitive enough to provide sufficient signal to calculate the depolarization ratio. Furthermore, these areas are of sufficiently low aerosol content as to be irrelevant to the topic at hand; so rather than make any assumption about them, depolarization ratios were simply not calculated in these areas. This is in contrast to times where no data were taken, which appear as vertical white stripes in both the backscatter and depolarization ratio plots.

\subsection{AERONET/AEROCAN}

AERONET (AErosol RObotic NETwork) is an inclusive federation of ground-based remote sensing networks in operation since 1993. Measurements of vertically integrated aerosol properties are accomplished using a CIMEL sunphotometer/sky radiometer (Holben et al., 1998). The AERONET programmatic goals are to assess aerosol optical properties and validate satellite retrievals of aerosol optical properties (http://aeronet.gsfc.nasa.gov/index.html). AEROCAN CIMELs (AEROCAN is the Canadian sub-network of AERONET) have been important in tracing the transport and characteristics of Asian dust layers across North America (e.g. Thulasiraman et al., 2002). The CIMEL instruments acquire solar irradiances across eight spectral channels (340, 
$380,440,500,670,870,1020$ and $1640 \mathrm{~nm}$ ) that are transformed into three processing levels of aerosol optical depth (AOD ) (1.0 - non-cloud screened; 1.5 - cloud screened; and 2.0 - cloud screened and quality assured).

In this study AOD spectra are used as inputs to the SDA (spectral deconvolution algorithm) in order to monitor total, fine- and coarse-mode AOD variations in relation to lidar profiles taken in Egbert, ON (see Fig. 2). These three quantities, which roughly correspond to sub-micron and supermicron radius regimes, are derived at a reference wavelength of $500 \mathrm{~nm}$ (O'Neill et al., 2003) and are standard products on the AERONET website. Their utility lies in the fact that aerosols and clouds can be roughly classified along bimodal lines; thus aerosol pollutants, biomass burning, smoke and volcanic sulphates are fine mode, while clouds, dust and volcanic ash are coarse mode. This robust characterization can be very useful in analysing lidar data if the sampling frequency of sunphotometry data is comparable to the lidar frequency. For high-frequency comparisons with lidar data we employed Level 1.0 data as input to the SDA while reserving lower-frequency Level 2.0 data for temporal scales running from hours to days. The non cloud-screened Level 1.0 data is preferred because one can then observe, in comparison with the lidar data, all the dynamics of clear and cloudy lines of observation (and use the SDA to spectrally separate clouds). Level 1.0 data is calibration corrected. The AERONET protocol, whatever the level of the data, is to publish AOD results that have only undergone a pre-calibration of the sunphotometer's extraterrestrial calibration coefficient before the regular deployment of the sunphotometer and then re-publish the AOD results as a linear trend between the preand post-calibration coefficients, once the sunphotometer returns from its regular deployment.

In a separate operational mode, almucanter sky radiances are collected across four channels $(440,670,870$, and $1020 \mathrm{~nm}$ ) at a nominal sampling resolution that is about $1 / 20$ of the nominal AOD sampling resolution ( $1 \mathrm{~h}$ versus $3 \mathrm{~min}$ ). The sky radiances, along with AOD estimates at the same four channels, are used to perform inversions for particle size distribution and refractive index (Dubovik and King, 2000). The size distribution and refractive index results are then employed to compute auxiliary parameters such as the total, fine- and coarse-mode optical depth (analogous to the SDA parameters) and other modal parameters. The Dubovik inversion is used in this paper to investigate Asian to North American trends in the particle size distributions for known dust events and to help characterize the bi-modal behaviour of dust aerosol particle size distributions.

\subsection{HYSPLIT}

Back trajectories were calculated using the HYSPLIT (HYbrid Single-Particle Lagrangian Integrated Trajectory) model Version 4. HYSPLIT 4 is the current version of a complete system for computing simple air parcel trajectories to com- plex dispersion and deposition simulations for any location and date (depending on data availability) using a variety of standard data input products (e.g. the NCEP Reanalysis 1948-present). All meteorological data used for this study were taken from Global Data Assimilation System (GDAS) $1^{\circ} 3 \mathrm{P}$ weekly files generated by the National Climactic Data Center (NCDC). In this study, the layers of interest were observed over a range of altitudes and individual events continued for several days. In order to give a full picture of the paths taken by the air parcels in question, an array of back trajectories were calculated for each event. For each day during which dust was detected, back trajectories were originated in $6 \mathrm{~h}$ intervals throughout the altitude regions where dust layers were observed, in $200 \mathrm{~m}$ increments. The time spans for which parcels were traced back was selected on a case-bycase basis, but for each trajectory calculated the time step was $1 \mathrm{~h}$. Due to the large number of trajectories calculated, the results were plotted in "frequency mode", which is essentially a $2 \mathrm{D}$ histogram in $1^{\circ}$ increments, rather than individually.

\subsection{NAAPS}

The Navy Aerosol Analysis and Prediction System (NAAPS) is an Eulerian system for predicting the distribution of tropospheric aerosols based upon the work of Christensen (1997). It uses global meteorological fields from the Navy Operational Global Atmospheric Prediction System (NOGAPS) analyses and forecasts on a $1^{\circ}$ by $1^{\circ}$ grid, at $6 \mathrm{~h}$ intervals, for 24 vertical levels reaching $100 \mathrm{mb}$. NAAPS provides global $120 \mathrm{~h}$ forecasts of smoke, sulfate, and dust distributions in near-real time. Dust emission in the model occurs whenever the friction velocity from wind exceeds a threshold value (currently set at $0.6 \mathrm{~m} \mathrm{~s}^{-1}$ ), snow depth is less than a critical value (current value is $0.4 \mathrm{~cm}$ ), and the surface moisture is less than a critical value (critical value set to 0.3 ). When these conditions are met, the particle flux is calculated and injected into the bottom two layers of the model. In NAAPS, the particle flux is scaled to include only particles with radii less than $5 \mu \mathrm{m}$. The dust prediction model is based upon a combination of observed and predicted weather patterns with a global map of known dust emission areas. Dust emission areas are derived from eight of the 94 land use types used in the USGS Land Cover Characteristics database, which was developed from Advanced Very High Resolution Radiometer (AVHRR) data and has $1 \mathrm{~km}$ resolution. Some subjective modifications were made to the land use data based on observable evidence when dust source regions were selected (e.g. regions designated "low sparse grassland" were defined as source regions only in China and Mongolia despite existing in other regions such as New Zealand and North America). The flux from a given $1^{\circ}$ by $1^{\circ}$ grid cell is scaled based upon the fraction of land use that fits within one of the eight designated land use categories. For all areas not designated as dust source regions, the friction velocity threshold is set to infinity. 

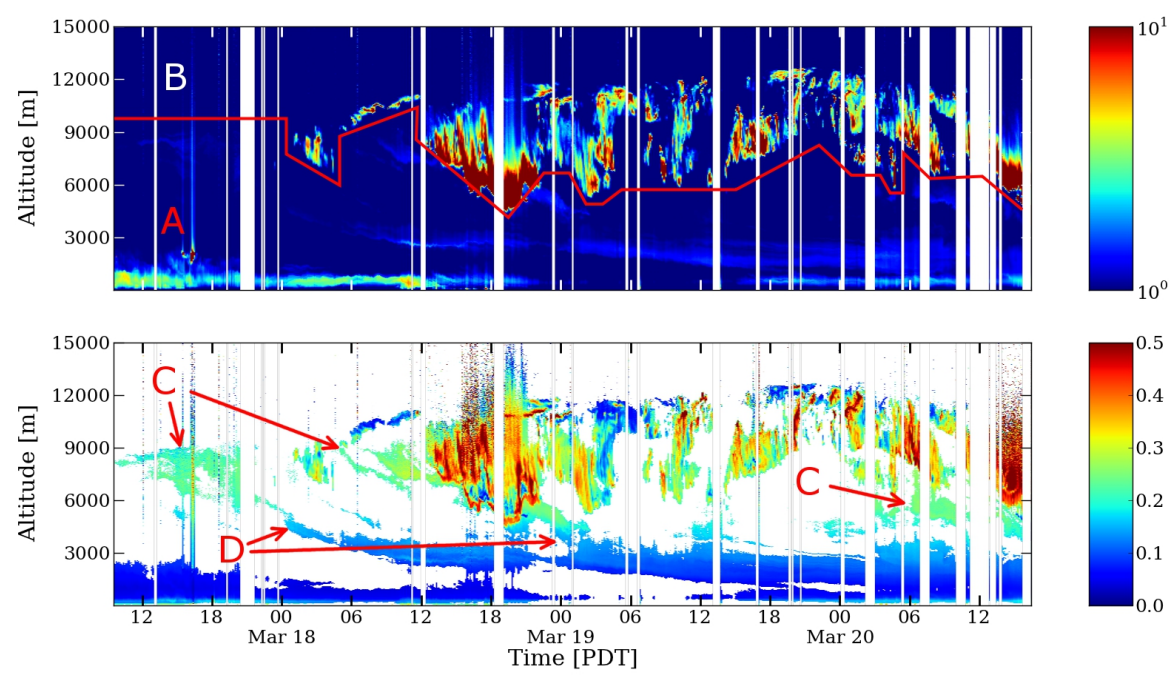

a) 17-20 March, 2010
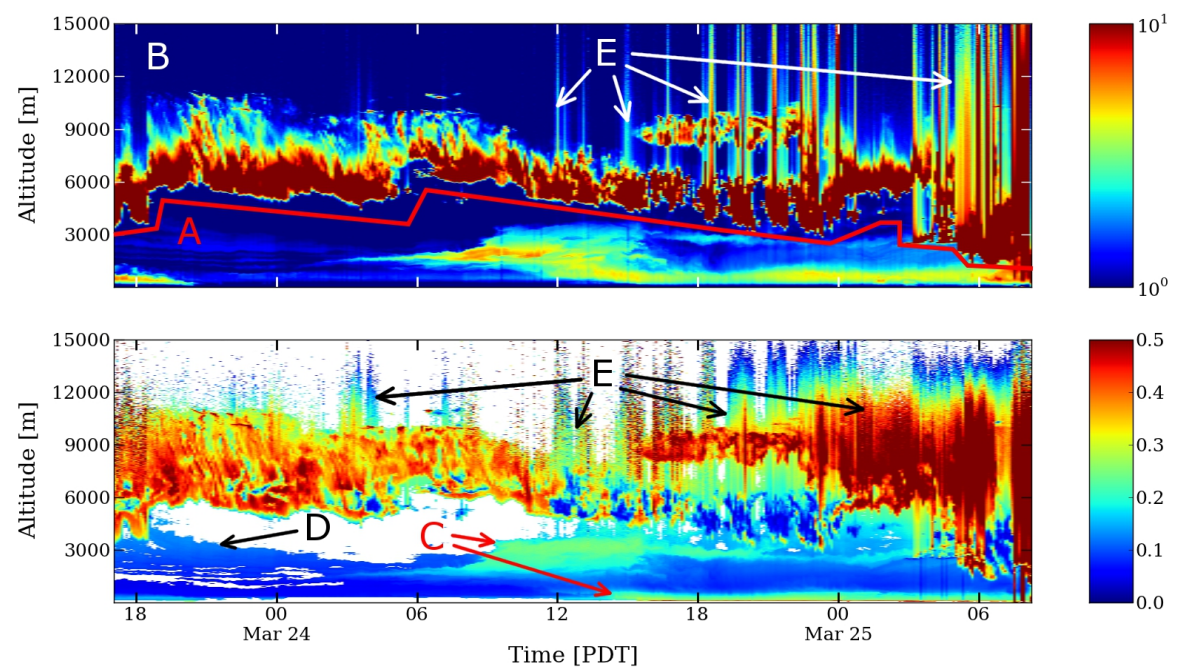

b) 23-25 March, 2010

Fig. 3. CORALNet false-colour plots for two dust events in Vancouver, BC, during March 2010. (a) Lidar observations for 17-20 March 2010 showing $1064 \mathrm{~nm}$ backscatter ratios (top) and masked $532 \mathrm{~nm}$ depolarization ratios (bottom). The red line divides the backscatter ratio plot into Region A, which is dominated by aerosols, and Region B, which is mostly clouds. Areas marked C are typified by high depolarization ratios, likely to contain high concentrations of dust. Areas marked D show reduction in depolarization probably due to mixing with fine-mode aerosols. (b) Lidar observations for 23-25 March 2010 showing $1064 \mathrm{~nm}$ backscatter ratios (top) and masked $532 \mathrm{~nm}$ depolarization ratios (bottom). The red line divides the backscatter ratio plot into Region A, which is dominated by aerosols, and Region B, which is mostly clouds. The areas marked $\mathrm{C}$ are defined by high depolarization ratios as dust. The background aerosols surrounding the dust layer are marked D. E indicates artefacts above optically thick layers that are not real features. As the clouds descend, note the transition in depolarization plots from ice (orange and red) to water (blue).

\section{Results}

\subsection{CORALNet observations}

Dust was clearly visible in CORALNet lidar data in March and April in multiple layers throughout the troposphere at both locations. The layers were identified as dust and distinguished from local mixed-layer aerosols through the com- bined analysis of lidar backscatter and depolarization ratio plots.

Dust particles tend to be highly non-spherical and thus exhibit a high degree of depolarization, although studies of dust from the deserts of Asia have shown a marked variation of depolarization ratio as a function of source region. Kai et al. (2008) observed dust from the Taklamakan Desert in 2002 with linear volume depolarization ratios from 0.17 to 0.33 
with a typical value of $\sim 0.29$. (Note that Kai et.al. used an equivalent but non-standard definition of depolarization ratio and the values reported here have been converted to the standard linear depolarization ratio values as defined in Eq. 4). Liu et al. (2012) observed particle depolarization ratios $20 \%$ lower in the Gobi Desert than the Taklamakan. They also presented volume depolarization ratios generated by CALIPSO from the 2010 event near the west coast of North America that ranged from $0.10-0.20$. Liu et al. (2012) postulate that, as dust-rich layers from these source regions are transported eastward, the depolarization ratios decrease due to the combined effects of gravitational settling of the largest particles, downstream mixing between source regions, and the introduction of fine-mode aerosols (primarily sulfates and nitrates) from industrial centres in China, Korea, and Japan. This is supported by several other studies as well (e.g. Mori et al., 2003; Clarke et al., 2004; Li et al., 2012).

Despite this range of variation, depolarization ratios are still useful in distinguishing dust from other aerosols because other spherical and fine-mode particles have much lower depolarization ratios with median values typically below 0.02 (Omar et al., 2009). Thus even a qualitative examination of depolarization ratios alongside backscatter ratios can prove illuminating when trying to distinguish the presence of elevated dust layers such as these. In the lidar data collected for this study the well-mixed boundary layers in Vancouver and Egbert, prior to the apparent intermingling of subsiding layers from above, exhibit volume depolarization ratios 150 $500 \%$ lower than the layers identified as rich in Asian dust.

\subsubsection{March 2010}

Specific observations of elevated aerosol layers were made at UBC from 17-20 March and again on 24 March (Fig. 3) These events pre-dated the observations of long-range transport made by previous authors (e.g. Uno et al., 2011; Fischer et al., 2011; Liu et al., 2012) but coincided with mid-March wind storms in that region ( $\mathrm{Li}$ et al., 2012). In order to verify the presence of desert dust, depolarization ratios were calculated from the $532 \mathrm{~nm}$ data.

The first event occurred between 17 and 20 March. As shown in Fig. 3, false-colour images of backscatter ratio from the $1064 \mathrm{~nm}$ channel show the dust layers entered the lidar field-of-view at an altitude of 6-9 km at noon on 17 March. At this point the mean volume depolarization ratio of the elevated layers was around 0.25 . Combined with backscatter ratios well below what would be expected for clouds, this is a strong indication of dust. The depolarization ratio differentiates this layer clearly from the well-mixed layer covering the bottom $2.5 \mathrm{~km}$ of the troposphere, which maintains a consistent depolarization ratio of $<0.1$. Over time, presumably through a combination of subsidence and gravitational settling, both layers appeared to move downward. Interestingly, as the dust layers subsided toward the boundary layer, the depolarization ratio was steadily reduced to 0.1 or below.
In general terms it seems that above an altitude of $\sim 4 \mathrm{~km}$ the depolarization ratio remains above 0.2 , indicating a relatively high concentration of dust within the layers. Below that, the ratio falls rapidly, indicating a higher proportion of fine-mode aerosols. The observed trend in mixing is a consistent feature of the observations at UBC; the dust layers observed in Fig. 4 exhibit much the same behaviour.

The dust layer observed in the lower troposphere in Vancouver on 24-25 March, shown in Fig. 3b, is anomalous among these examples in that it is not seen to include a series of multiple optically thin layers in the middle to upper altitudes of the free troposphere with gradually increased mixing in the lower altitudes. In this instance, a single, continuous layer is observed near the surface below a consistent cloud deck and is clearly distinguishable from the aerosols that surround it in both the backscatter and depolarization ratio plots. This layer exhibits far higher optical depth than any other dust layer observed in this study, as evidenced by the unusually high backscatter ratios. The depolarization ratios exhibit the typical characteristics of desert dust, with a relatively high mean depolarization ratio exceeding 0.22 . The presence of the layer above the lidar is short lived compared to other instances, and there is little apparent mixing with the surrounding aerosols. The time period from 15:00, 24 March-09:00, 25 March (PDT) is also the only time that the lidar detected a strong signal from unmixed dust in the lower $1 \mathrm{~km}$ above the ground. These observations were accompanied by an increase in $\mathrm{PM}_{10}$ concentrations to $28 \mu \mathrm{g} \mathrm{m}^{-3}$ at Vancouver International Airport. Surface level pressure maps of the area show the passing of a ridge of high pressure aloft with subsiding winds during this time period, which is consistent with the observation of relatively high optical depth dust layers close to the ground. (NAAPS-NOGAPS timeheight sections from nearby Cheeka Peak, WA, exhibiting this trend can be found in the Supplement to this article.) With the passing of the front on 25 March, the dust over the lidar was quickly removed. NAAPS time-height sections from nearby Cheeka Peak, roughly $100 \mathrm{~km}$ south-west of Vancouver, showed a similar structure with increased concentrations of dust near the surface from 10:00, 23 March to $04: 00,25 \mathrm{March}$, at which point surface concentrations of dust sharply declined.

\subsubsection{April 2010}

Layers appearing to result from Asian dust storms were again observed by CORALNet in Vancouver on 9-12 April 2010. Investigation of the lidar backscatter ratio plots indicates that, similar to 17-20 March, by the time the dust had reached Vancouver, it had developed a complex vertical structure comprising multiple sub-layers, the thickest of which were concentrated at altitudes from 3-6 km (Fig. 4 top panel). Backscatter ratio plots indicate that the layers were subsiding, with the primary layer dropping from $6 \mathrm{~km}$ to $3 \mathrm{~km}$ during the course of the first day, while layers that originated 
below $4 \mathrm{~km}$ entered the mixed layer by the end of the day and were likely deposited to the ground soon afterwards. Backscatter ratios show these layers to be optically thicker than those observed during the similar event in March. By 13 April, the $6 \mathrm{~km}$ layer had subsided and appears to have been entrained into the mixed layer as well. Just as in the events of March, the depolarization ratios clearly identify these layers as dust, with initial ratios of 0.20 or higher (Fig. 4 bottom panel). Also as in the March case (Fig. 3a), as the layers subsided toward the mixed layer, the depolarization ratios decreased. For the primary dust layer, the mean volume depolarization ratio dropped from 0.2 to 0.1 over the course of two days.

The lidar observations from Egbert show a similar pattern five days later, but with many important differences (Fig. 5). At this location, the elevated layers are originally seen briefly at around midnight on 18 April distributed over altitudes from $5-8 \mathrm{~km}$. An elevated layer was detected prior to this on 18 April, but the depolarization ratios for this layer are low, remaining under 0.1 (Region B in middle panel of Fig. 5). This is an indication that for this time period this layer is dominated by aerosols other than dust, although associated fine-coarse-mode optical depth inversions show a steady increase of the coarse mode through this time period, indicating an increase in the amount of dust over time (bottom panel of Fig. 5). This observation was corroborated by back-trajectory analysis for 18 April showing trajectories that were widely distributed, not focused over the Asian source regions. After a break during the first half of the day on 19 April, the primary layer is observed by the lidar. Backscatter ratios show that unlike the Vancouver events, which were separated into multiple distinct layers, this dust was more homogeneously distributed from 3-8 km. After 20 April, the highest concentration occurred from $3-4 \mathrm{~km}$ with the layer remaining optically thinner above. In addition to this, a consistent, optically thick boundary layer $1.5-2 \mathrm{~km}$ deep and apparently consisting of mostly fine-mode particles with depolarization ratios below 0.05 is present throughout the observation period. Entrainment and settling seem to draw the elevated layer down to the edge of the boundary layer from 19-20 April, but after that the altitude of the layer stabilizes and depolarization ratios reveal that little mixing seems to occur during the course of the event. Throughout the event, the dust appears embedded in a background layer of particles with lower depolarization ratios $(<0.1)$, indicating a mixture of dust with other particles. As before it is not possible to determine the exact nature of these particles from the lidar data, but such low depolarization ratios are typical of fine-mode aerosols (e.g. sulfates, nitrates, or organic carbon). It is also clear that by the time the dust layers travelled across North America to Egbert, the mean volume depolarization ratios within the dust layers had been reduced substantially. The maximum depolarization ratio observed within the dust layers over Egbert was 0.15 , as compared to 0.27 over Vancouver. This could have been the result of continued loss of dust through depo- sition, external mixing with the aforementioned background layer or more likely a combination of both. Less likely is the possibility of continued internal mixing as dust particles were coated with nucleated gases such as sulfates or nitrates, because although this type of atmospheric process for dust has been observed and documented repeatedly for relatively young dust particles (e.g. Tang et al., 2004; Li et al., 2012) there is no evidence the dust particles would continue to accrue further coatings after so many days aloft. Although lower than that observed during the Vancouver events, the depolarization ratio for this layer is clearly within the lower end of the range that indicates the presence of dust. The contrast in the depolarization ratios clearly distinguishes this layer as having a different composition than its surroundings. Considering the large distance between the source and the observation and the likelihood of mixing in the interim, it is to be expected that the depolarization ratios would be lower than those observed on the west coast. It is clear that this layer contains a much higher dust content than the local aerosols observed in the boundary layer below it.

Perhaps more interestingly, along with a net reduction in volume depolarization ratio, the dust layers appear to show more consistency in optical properties over time and altitude than those observed in Vancouver. With the exception of the unique event on 24 March, each of the Vancouver events showed subsiding dust layers for which the depolarization ratios dropped from over 0.20 to 0.10 or below during the course of the four-day observation period as they approached the ground. This is a good indication that the composition of the layers was still changing rapidly. For the layers observed over Egbert, the initial depolarization ratio was lower, but the ratio was consistent for all altitudes and remained almost totally constant during the entire four-day period for which it was visible (Fig. 5). This qualitative observation is consistent with Ryder et al. (2013), who observed what they called a "weakly exponential" trend in the evolution of mean particle diameter, single scattering albedo, and other optical properties as a function of age.

\subsection{AERONET observations}

Figure 5 shows the variation of the Egbert optical depths lined up with the aforementioned backscatter and depolarization profiles. SDA results are plotted as solid circles (black, red and blue representing total, fine- and coarse-mode optical depths), while the analogue quantities from the Dubovik inversion results are plotted as large Xs. Unlike the events monitored in Vancouver, where cloud cover precluded the gathering of usable sunphotometer data, this event was largely cloud free, making it possible to observe the correlation between the variation of the coarse-mode optical depth and the backscatter strength of the dust plumes. For example, the dust event that can be seen in the lidar backscatter plot to start after 12:00 (EDT) on 19 April is captured in the coarse-mode optical depth variation, including a peak in coarse-mode 

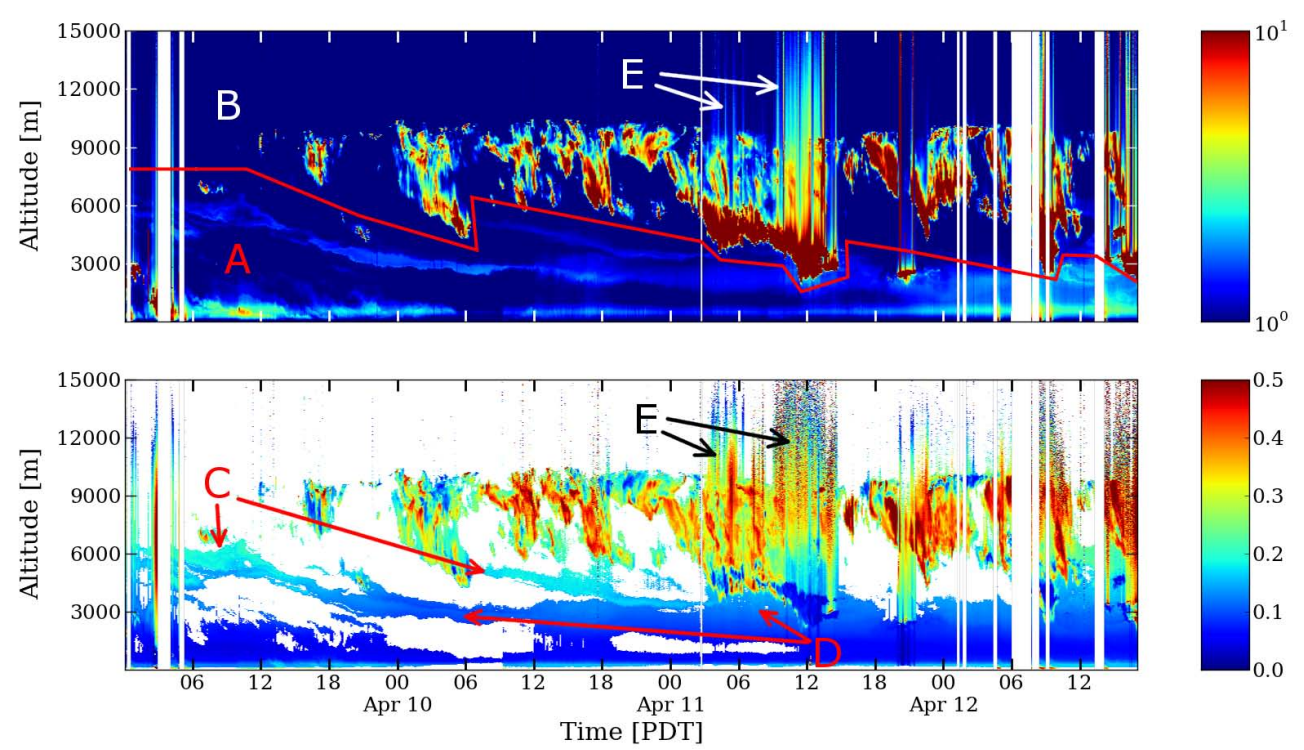

Fig. 4. Lidar observations for Vancouver, BC, from 9-12 April 2010: $1064 \mathrm{~nm}$ backscatter ratios (top) and masked 532 nm depolarization ratios (bottom). The red line divides the backscatter ratio plot into Region A, which is dominated by aerosols, and Region B, which is mostly clouds. Areas marked C are typified by high depolarization ratios, likely to contain high concentrations of dust. Areas marked D show reduction in depolarization probably due to mixing with other aerosols. The areas marked $\mathrm{E}$ are artefacts due to optically thick layers below and are not real features. In clouds note the distinct difference between dark blue areas (water) and red-orange areas (ice).

optical depth where one can qualitatively see that the integrated backscatter signal would be a maximum. The increase in high-frequency noise from 10:00-12:00 (EDT) on 21 April is the result of clouds as seen in the lidar data at $\sim 6 \mathrm{~km}$.

The diurnal behaviour of the fine-mode optical depth is rather complex in relation to the behaviour of the coarsemode optical depth, but the comparison between the Dubovik inversion and the SDA is broadly consistent. The differences between the high-frequency SDA optical depths and the lowfrequency Dubovik optical depths are in part due to retrieval errors but also to differences in the method whereby the fine and coarse modes are defined (the former uses an optical definition while the latter uses a simple radius cut-off between the two modes; see O'Neill et al., 2003). The radius cut-off effect is particularly important when the coarse-mode distribution straddles the fine-mode regime, as it does for the case of small dust particles. It should also be noted that the SDA outputs are quite sensitive to the spectral shape of the AODs. If there is a change in this spectral shape, as occurred between the pre-calibrated SDA outputs and the post-calibrated correction, then one can observe changes in the diurnal variation that can constitute a substantial fraction of the SDA AODs. If one believes that the post-calibration correction effectively eliminated any major calibration problems, then this is not a problem, but it is a demonstration of the effect of changes in AOD spectral shape.

Figure 6 shows a scattergram between the Dubovik retrievals of these parameters for Egbert during the month of
April. The points in blue represent the Fig. 5 event of 18-12 April for coarse-mode optical depths greater than approximately 0.04 . The reported $R^{2}$ value of 0.64 for a linear fit indicates that the correlation is significant. The existence of such a correlation is consistent with an analogous relationship between Dubovik retrievals of the bulk particle volume density of each mode. A similar observation for the 2005 Saharan dust event in Vancouver, as well as a discussion and brief literature review on the existence of a fine mode for dust, was presented in McKendry et al. (2007). Since the 2005 Saharan results were obtained from Version 1 Dubovik retrievals, the data were re-analysed using Version 2 retrievals: this is a necessary check since Version 1 did not account for the non-sphericity of dust particles and it has been shown that ignoring this fact can result in fine-mode artefacts (Dubovik et al., 2002). The results were essentially the same with fine- and coarse-mode optical depths and volume concentrations displaying a similar degree of correlation. Other authors have observed or inferred a fine-mode dust component from AERONET inversions (e.g. Eck et al. (2008) in the case of U.A.E. dust, Kubilay et al. (2003) for Saharan Dust, and Tratt et al. (2001) for Asian dust), while there is some evidence for a fine-mode dust aerosol from microphysical impactor measurements (Gomes et al., 1990). However, while these observations are intriguing, the inferrence that a correlation between fine- and coarse-mode optical depths suggests the existence of a fine-particle dust mode has to be tempered by findings such as Dey et al. (2004), who found no evidence of a fine mode in their AERONET 

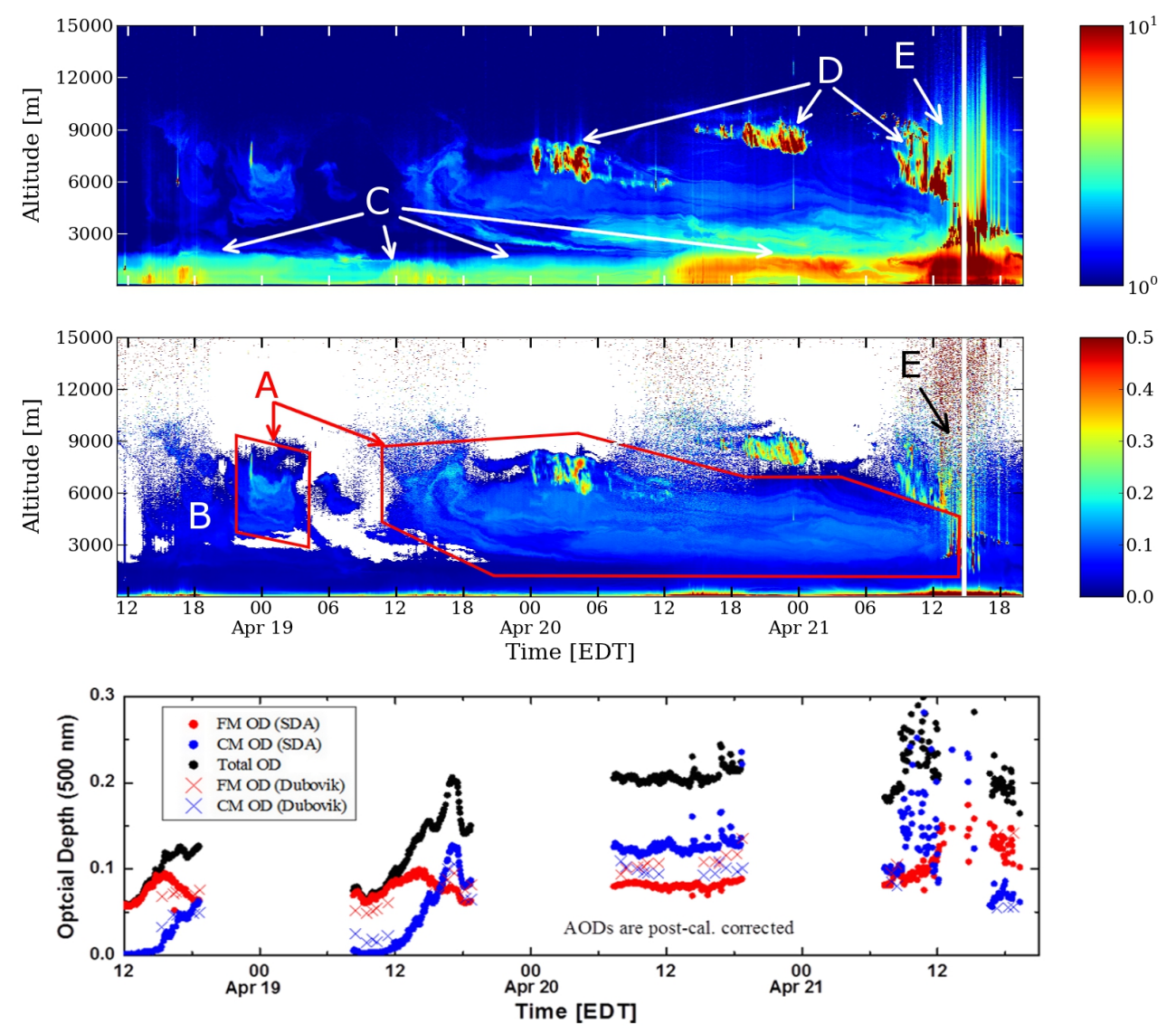

Fig. 5. Lidar observations and AEROCAN retrievals for Egbert, ON, from 18-21 April 2010: the top two panels show the familiar 1064 nm backscatter ratios (top) and masked $532 \mathrm{~nm}$ depolarization ratios (middle). Depolarization ratios identify Region A as dust. Region B indicates a larger contribution from background aerosols with low de-polarization ratios from other sources. Region $\mathrm{C}$ is the atmospheric boundary layer. Areas marked D are clouds. The area marked $\mathrm{E}$ is an artefact of optically thick layers below and is not a real feature. The bottom panel shows an optical depth plot that is co-aligned in time with the lidar plots and represents the results of the SDA (solid circles) and the Dubovik retrievals (large Xs) for fine- and coarse-mode optical depth. For both types of retrieval, red markers indicate the fine mode and blue markers the coarse mode. Black markers represent the total AOD. The Egbert sunphotometer and the Egbert CORALNet lidar are co-located within a few tens of metres.

retrievals during Saharan dust events, and Reid et al. (2003), who observed that impactor measurements may create artificial fine-mode aerosols from particle bounce and break-up effects, particularly in the case of aggregates. Furthermore, Reid et al. (2003) point out that two different inversion algorithms (Dubovik and Nakajima) applied to AERONET data acquired during Saharan dust events yielded a fine-mode dust presence in the former case and no such presence in the latter case. Finally, it is worth noting that, while a correlation was found between the fine- and coarse-mode optical depths in the Dubovik inversions, the SDA retrievals yielded no such correlation. One possible explanation for this is a difference in definition of modes. The Dubovik approach tends to eliminate a fraction of the coarse mode to the benefit of the fine mode, thus tending to increase the likelihood of an apparent correlation of the two modes in the presence of high levels of coarse-mode AOD. Another possible explanation is a prob- lem with one or more of the CIMEL channels which could alter the SDA results. As the Dubovik inversion is dependant on almucantar radiance as well as the AOD spectra, it would be less sensitive to this.

The presence of externally mixed fine-mode particles from anthropogenic sources represents an intriguing alternative argument for the fine-coarse-mode correlation at Egbert. Heald et al. (2006) indicate that Chinese $\mathrm{SO}_{2}$ pollution over the Pacific escapes relatively efficiently into the free troposphere where oxidation and nucleation processes act to form fine-mode sulfates that are transported to the US mainland. They then appealed to high-elevation IMPROVE network measurements acquired in the north-west US to show that dust concentrations for the 2001 Asian dust event were correlated with above-background increases in anthropogenic sulfates that they traced to Asian pollution. This argument is 


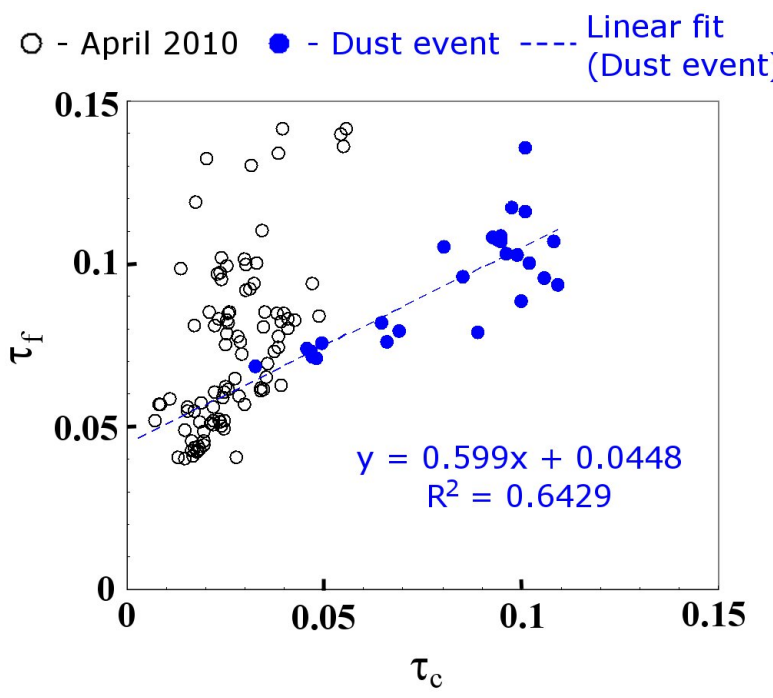

Fig. 6. Fine-mode optical depths $\left(\tau_{\mathrm{f}}\right)$ versus coarse-mode optical depths $\left(\tau_{\mathrm{c}}\right)$ during the month of April at the Egbert site. Filled blue circles represent points classified as dust, and hollow black circles represent all other points from April. The optical depths were obtained from the Dubovik Version 2, Level 1.5 retrieval results.

generally applicable to the Egbert case since the back trajectories of Fig. 7 do pass over industrial China and Japan.

\subsection{NAAPS and HYSPLIT model results}

NAAPS models from the spring of 2010 predicted aerosol optical thickness in excess of 0.8 for dust in the air above central Asia, including the Gobi and Taklamakan regions, for multiple sustained periods during March and April. Concentrations this high occur almost exclusively over dustproducing regions under conditions of high winds. This is a strong indication that these regions were the source of the dust layers that spread out across the Pacific throughout March and April, in agreement with Uno et al. (2011) and Li et al. (2012). Furthermore, these models predicted that the total integrated AOD from dust in the troposphere over CORALNet installations in Vancouver and Egbert was high enough to be detectable. In order to confirm the connection between this dust and layers observed in lidar data, HYSPLIT back trajectories were calculated for the regions and times in question to show the progress of the air parcels containing the dust as they approached the lidar installations.

For locations such as Vancouver and Egbert, in the midlatitude westerlies, it is often the case that for trajectories of more than a couple of days in duration the majority of parcels come from a generally westward direction, and this is indeed the case for most of the days reported here. More important to note is how tightly the trajectories are grouped and how many of them pass directly over the regions where the aforementioned dust storms were occurring.
NAAPS predictions show dust first reaching the west coast of North America on 15 March. Throughout the periods in March during which dust was detected by the lidar, the NAAPS models consistently showed dust AOD levels of 0.10.2 over the west coast of North America from southern British Columbia down to northern California. A representative example of this from 19 March is seen in Fig. 7a.

Based on lidar observations, a starting altitude range of 3-9 km was selected for HYSPLIT back trajectories for this event. Tightly grouped back trajectories for this altitude range and date (Fig. 7a) are consistent with an Asian dust source and confirm that this event occurred one week prior to the earliest event identified in Fischer et al. (2011) and almost a full month earlier than the events described in Uno et al. (2011). For this day, air parcels were tracked backwards for a duration of $180 \mathrm{~h}$.

As the dust storms in Asia continued into April, the NAAPS results predicted the continued presence of high concentrations of dust in the aforementioned desert regions. At the same time, layers continued to arrive over North America. For the first 10 days of April the majority of the dust followed a more southern path across the Pacific than was observed during the events of March. The highest concentrations for early April were near the Canada-USA border, with lower concentration layers at times extending as far south as the Gulf of Mexico and north to Baffin Bay. This can be seen in Fig. 7b, which shows the back-trajectory frequency plot for 11 April based on $210 \mathrm{~h}$ back-trajectory duration and a starting altitude of 3-6 km (consistent with Vancouver lidar observations).

After 13 April, the NAAPS predictions showed the highest concentrations of dust well north of the Canada-USA border; over the next two days the layers of dust spread to engulf nearly all of Canada. This large dust layer persisted for another 10 days before finally starting to dissipate on 24 April. On some days, lower-concentration regions also extended to cover substantial portions of the US as well. A representative example of this distribution can be seen in Fig. 7c, taken on 20 April. This layer of dust was unusually large due to the extraordinary size and duration of dust storms in the deserts of central Asia, and it persisted over North America as a result of a large high-pressure system that dominated over Canada for several weeks.

Back trajectories from Egbert, Ontario, showed greater spread in the medium range compared to Vancouver back trajectories, with air parcels covering large portions of western North America and the Pacific. But, as exemplified in the trajectory frequency plot for 20 April (Fig. 7c), a significant portion of trajectories converge in the long range to pass over the deserts of Asia. Based on lidar observations from Egbert, the starting altitudes for these back trajectories was 3-9 km. After considering the HYSPLIT back trajectories for this area, we conclude that the observed dust originated from the Asian dust storms in early April. 


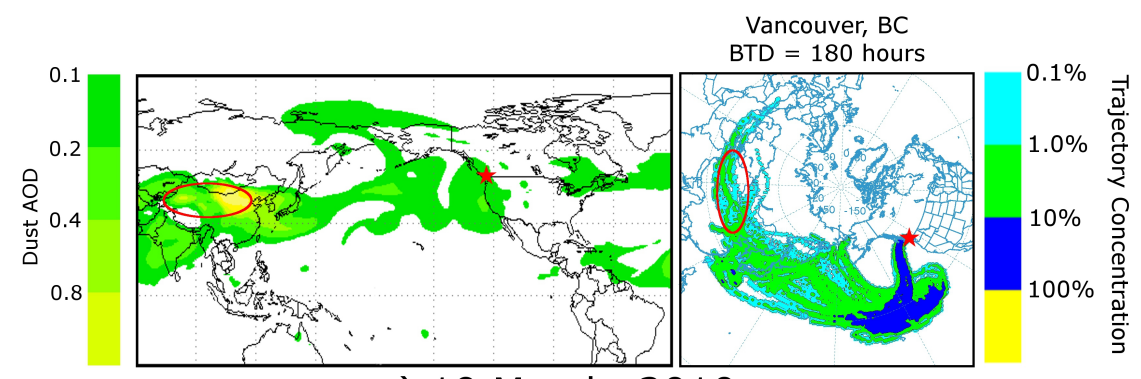

a) 19 March, 2010

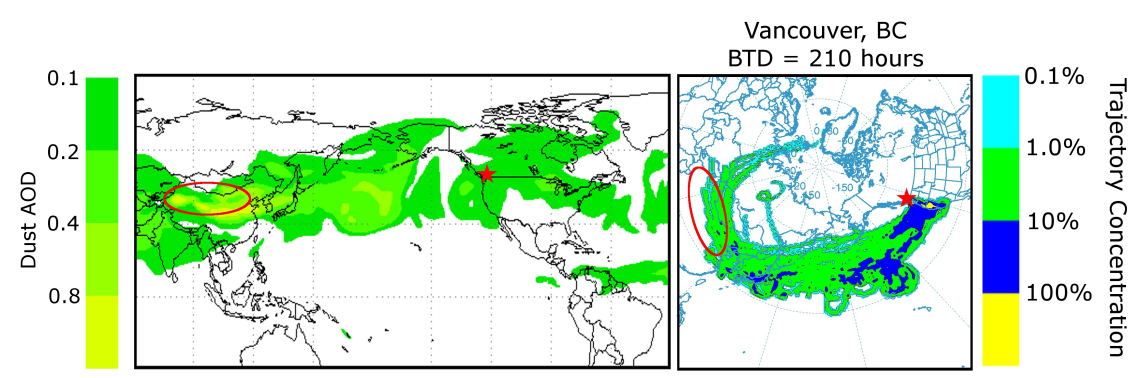

b) 11 April, 2010

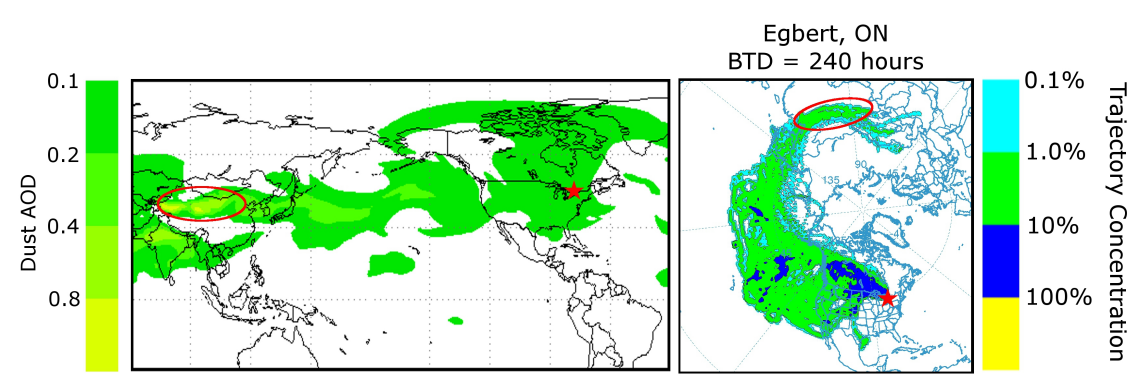

c) 20 April, 2010

Fig. 7. NAAPS global dust model results (left) alongside frequency plots of HYSPLIT back trajectories (right) for peak days during the three primary dust transport events observed by the CORALNet lidars. Dust models represent $24 \mathrm{~h}$ average values for the days in question. HYSPLIT plots include back trajectories that were calculated in $200 \mathrm{~m}$ increments throughout the altitudes of interest and repeated every $6 \mathrm{~h}$ for the day in question. HYSPLIT plot labels include the location from which trajectories were generated and the back-trajectory duration (BTD), or the number of hours air parcels were tracked for that day.

\section{Conclusions}

In this study modelled as well as empirical observations of an extraordinary example of springtime dust transport from Asia to North America were presented. The event was unusual among similar annual dust transport events in its size, spatial extent, and duration. The extent of the dust distribution was made evident with NAAPS global dust models. More detailed observations of the vertical structure of dust layers in Vancouver, BC, and Egbert, ON, were made with the use of CORALNet lidar imagery. The Egbert lidar observations constituted the first recorded lidar observation of Asian dust at this location. The specific layers in question were traced back to the regions where dust storms occurred through the use of multiple HYSPLIT back trajectories. This combina- tion of NAAPS models and HYSPLIT back trajectories along with sunphotometer and lidar data was used to show that dust from earlier storms in the Gobi region in March also reached the west coast of North America in observable quantities nearly a month prior to previous observations. Analysis of AERONET SDA results from the co-located site in Egbert was performed, showing marked increases in coarse-mode optical depth corresponding to the presence of relatively high-depolarization layers in the lidar data. Correlations between coarse- and fine-mode optical depths for known dust periods over Egbert revived questions about a controversial point: whether such a correlation was the result of an inversion artefact, whether the presence of fine-mode aerosols mixed externally with the dust layers, or whether it could 
potentially be ascribed to the presence of a fine-particle dust mode. By comparing the details of backscatter and depolarization ratios obtained from lidar imagery in April, a great deal was revealed about the vertical structure of the dust layers including clear differences between the dust layers that had only crossed the Pacific Ocean as compared to those that had traversed North America as well. In Vancouver, the dust was separated into multiple distinct layers that had very high initial depolarization ratios, indicating a relatively pure dust layer. These layers saw a marked decrease in depolarization ratio with altitude over the course of a few days. In contrast, the dust layer observed in Egbert appeared as a single mass distributed over several kilometres of altitude that had apparently undergone significant deposition and further mixing as it was transported across the continent. However, the layer showed little additional mixing with the surrounding aerosols during the days of observation. This layer began with a much lower depolarization ratio than those observed in Vancouver, but the ratio remained nearly constant throughout the days during which it was observed.

Taken together, these results complement the results of Uno et al. (2011), Fischer et al. (2011), Li et al. (2012) and Liu et al. (2012) regarding this event by revealing new details of the structure and dynamics of these layers over North America after weeks spent in the atmosphere. As such they demonstrate the utility of lidar and sunphotometer networks in investigating processes affecting long-range transport of aerosols, especially in cases where these two complementary instruments can be co-located in close proximity to one another.

\section{Supplementary material related to this article is available online at: http://www.atmos-chem-phys.net/13/ 4515/2013/acp-13-4515-2013-supplement.pdf.}

Acknowledgements. We gratefully acknowledge the NOAA Air Resources Laboratory (ARL) for the provision of the HYSPLIT transport and dispersion model used in this publication. We thank the PI investigators and their staff for establishing and maintaining the AEROCAN/AERONET site used in this investigation. We gratefully acknowledge the Naval Research Laboratory, Monterey for the use of NAAPS model results. We would like to acknowledge Bernard Firanski and Michael Travis of the lidar team at Environment Canada, without whose tireless efforts and valued input none of this research would have been possible. We would also like to acknowledge the valuable support work of the AEROCAN network manager Ihab Abboud of Environment Canada and the AEROCAN QA/processing coordinator Jim Freemantle. Finally, we are grateful to Environment Canada and NSERC for funds used to support this research.

Edited by: E. erasopoulos

\section{References}

Chin, Mian, Diehl, T., Ginoux, P., and Malm, W.: Intercontinental transport of pollution and dust aerosols: implications for regional air quality, Atmos. Chem. Phys., 7, 5501-5517, doi:10.5194/acp7-5501-2007, 2007.

Christensen, J.: The Danish Eulerian hemispheric model - A threedimensional air pollution model used for the Arctic, Atmos. Environ., 31, 4169-4191, 1997.

Clarke, A., Shinozuka, Y., Kapustin, V., Howell, S., Huebert, B., Doherty, S., Anderson, T., Covert, D., Anderson, J., Hua, X., Moore, K., McNaughton, C., Carmichael, G., and Weber, R.: Size distributions and mixtures of dust and black carbon aerosol in Asian outflow: Physiochemistry and optical properties, J. Geophys. Res.-Atmos., 109, D15S09, doi:10.1029/2003JD004378, 2004.

Dey, S., Tripathi, S., Singh, R., and Holben, B.: Influence of dust storms on the aerosol optical properties over the Indo-Gangetic basin, J. Geophys. Res.-Atmos., 109, D20211, doi:10.1029/2004JD004924, 2004.

Dubovik, O. and King, M.: A flexible inversion algorithm for retrieval of aerosol optical properties from Sun and sky radiance measurements, J. Geophys. Res.-Atmos., 105, 20673-20696, 2000.

Dubovik, O., Holben, B., Lapyonok, T., Sinyuk, A., Mishchenko, M., Yang, P., and Slutsker, I.: Non-spherical aerosol retrieval method employing light scattering by spheroids, Geophys. Res. Lett., 29, 1415, doi:10.1029/2001GL014506, 2002.

Eck, T. F., Holben, B. N., Reid, J. S., Sinyuk, A., Dubovik, O., Smirnov, A., Giles, D., O’Neill, N. T., Tsay, S. C., Ji, Q., Mandoos, A. A., Khan, M. R., Reid, E. A., Schafer, J. S., Sorokine, M., Newcomb, W., and Slutsker, I.: Spatial and temporal variability of column-integrated aerosol optical properties in the southern Arabian Gulf and United Arab Emirates in summer, J. Geophys. Res.-Atmos., 113, D01204, doi:10.1029/2007JD008944, 2008.

Fairlie, T. D., Jacob, D. J., and Park, R. J.: The impact of transpacific transport of mineral dust in the United States, Atmos. Environ., 41, 1251-1266, 2007.

Fischer, E. V., Hsu, N. C., Jaffe, D. A., Jeong, M. J., and Gong, S. L.: A decade of dust: Asian dust and springtime aerosol load in the US Pacific Northwest, Geophys. Res. Lett., 36, L03821, doi:10.1029/2008GL036467, 2009.

Fischer, E. V., Perry, K. D., and Jaffe, D. A.: Optical and chemical properties of aerosols transported to Mount Bachelor during spring 2010, J. Geophys. Res.-Atmos., 116, D18202, doi:10.1029/2011JD015932, 2011.

Gomes, L., Bergametti, G., Coudegaussen, G., and Rognon, P.: Submicron Desert Dusts - a Sandblasting Process, J. Geophys. Res.Atmos., 95, 13927-13935, 1990.

Gong, S. L., Zhang, X. Y., Zhao, T. L., Zhang, X. B., Barrie, L. A., McKendry, I. G., and Zhao, C. S.: A simulated climatology of Asian dust aerosol and its trans-Pacific transport. Part II: Interannual variability and climate connections, J. Climate, 19, 104 122, 2006.

Heald, C. L., Jacob, D. J., Park, R. J., Alexander, B., Fairlie, T. D., Yantosca, R. M., and Chu, D. A.: Transpacific transport of Asian anthropogenic aerosols and its impact on surface air quality in the United States, J. Geophys. Res.-Atmos., 111, D14310, doi:10.1029/2005JD006847, 2006. 
Holben, B., Eck, T., Slutsker, I., Tanre, D., Buis, J., Setzer, A., Vermote, E., Reagan, J., Kaufman, Y., Nakajima, T., Lavenu, F., Jankowiak, I., and Smirnov, A.: AERONET - A federated instrument network and data archive for aerosol characterization, Remote Sens. Environ., 66, 1-16, 1998.

Husar, R. B., Tratt, D. M., Schichtel, B. A., Falke, S. R., Li, F., Jaffe, D., Gasso, S., Gill, T., Laulainen, N. S., Lu, F., Reheis, M. C., Chun, Y., Westphal, D., Holben, B. N., Gueymard, C., McKendry, I., Kuring, N., Feldman, G. C., McClain, C., Frouin, R. J., Merrill, J., DuBois, D., Vignola, F., Murayama, T., Nickovic, S., Wilson, W. E., Sassen, K., Sugimoto, N., and Malm, W. C.: Asian dust events of April 1998, J. Geophys. Res.-Atmos., 106, 18317-18330, 2001.

Jaffe, D., McKendry, I., Anderson, T., and Price, H.: Six 'new' episodes of trans-Pacific transport of air pollutants, Atmos. Environ., 37, 391-404, 2003.

Kai, K., Nagata, Y., Tsunematsu, N., Matsumura, T., Kim, H.-S., Matsumoto, T., Hu, S., Zhou, H., Abo, M., and Nagai, T.: The structure of the dust layer over the Taklimakan desert during the dust storm in April 2002 as observed using a depolarization lidar, Journal of the Meteorological Society of Japan, 86, 1-16, 2008.

Kim, S.-W., Yoon, S.-C., Kim, J., and Kim, S.-Y.: Seasonal and monthly variations of columnar aerosol optical properties over east Asia determined from multi-year MODIS, LIDAR, and AERONET Sun/sky radiometer measurements, Atmos. Environ., 41, 1634-1651, 2007.

Kubilay, N., Cokacar, T., and Oguz, T.: Optical properties of mineral dust outbreaks over the northeastern Mediterranean, J. Geophys. Res.-Atmos., 108, 4666, doi:10.1029/2003JD003798, 2003.

Li, J., Wang, Z., Zhuang, G., Luo, G., Sun, Y., and Wang, Q.: Mixing of Asian mineral dust with anthropogenic pollutants over East Asia: a model case study of a super-duststorm in March 2010, Atmos. Chem. Phys., 12, 7591-7607, doi:10.5194/acp-127591-2012, 2012.

Liu, Z., Duncan Fairlie, T., Uno, I., Huang, J., Wu, D., Omar, A., Kar, J., Vaughan, M., Rogers, R., Winker, D., Trepte, C., Hu, Y., Sun, W., Lin, B., and Cheng, A.: Transpacific transport and evolution of the optical properties of Asian dust, J. Quant. Spectrosc. Ra., 116, 24-33, 2012.

McKendry, I. G., Strawbridge, K. B., O’Neill, N. T., Macdonald, A. M., Liu, P. S. K., Leaitch, W. R., Anlauf, K. G., Jaegle, L., Fairlie, T. D., and Westphal, D. L.: Trans-Pacific transport of Saharan dust to western North America: A case study, J. Geophys. Res.-Atmos., 112, D01103, doi:10.1029/2006JD007129, 2007.

McKendry, I. G., Macdonald, A. M., Leaitch, W. R., van Donkelaar, A., Zhang, Q., Duck, T., and Martin, R. V.: Trans-Pacific dust events observed at Whistler, British Columbia during INTEXB, Atmos. Chem. Phys., 8, 6297-6307, doi:10.5194/acp-8-62972008, 2008.

Mori, I., Nishikawa, M., Tanimura, T., and Quan, H.: Change in size distribution and chemical composition of kosa (Asian dust) aerosol during long-range transport, Atmos. Environ., 37, 42534263, 2003.
Omar, A. H., Winker, D. M., Kittaka, C., Vaughan, M. A., Liu, Z., Hu, Y., Trepte, C. R., Rogers, R. R., Ferrare, R. A., Lee, K.-P., Kuehn, R. E., and Hostetler, C. A.: The CALIPSO Automated Aerosol Classification and Lidar Ratio Selection Algorithm, J. Atmos. Ocean. Tech., 26, 1994-2014, 2009.

O’Neill, N., Eck, T., Smirnov, A., Holben, B., and Thulasiraman, S.: Spectral discrimination of coarse and fine mode optical depth, J. Geophys. Res.-Atmos., 108, 4559, doi:10.1029/2002JD002975, 2003.

Reid, J., Jonsson, H., Maring, H., Smirnov, A., Savoie, D., Cliff, S., Reid, E., Livingston, J., Meier, M., Dubovik, O., and Tsay, S.: Comparison of size and morphological measurements of coarse mode dust particles from Africa, J. Geophys. Res.-Atmos., 108, 8593, doi:10.1029/2002JD002485, 2003.

Ryder, C. L., Highwood, E. J., Rosenberg, P. D., Trembath, J., Brooke, J. K., Bart, M., Dean, A., Crosier, J., Dorsey, J., Brindley, H., Banks, J., Marsham, J. H., McQuaid, J. B., Sodemann, H., and Washington, R.: Optical properties of Saharan dust aerosol and contribution from the coarse mode as measured during the Fennec 2011 aircraft campaign, Atmos. Chem. Phys., 13, 303325, doi:10.5194/acp-13-303-2013, 2013.

Stohl, A., Eckhardt, S., Forster, C., James, P., and Spichtinger, N.: On the pathways and timescales of intercontinental air pollution transport, J. Geophys. Res.-Atmos., 107, 4684, doi:10.1029/2001JD001396, 2002.

Strawbridge, K. B.: Developing a portable, autonomous aerosol backscatter lidar for network or remote operations, Atmos. Meas. Tech., 6, 801-816, doi:10.5194/amt-6-801-2013, 2013.

Tang, Y., Carmichael, G., Kurata, G., Uno, I., Weber, R., Song, C., Guttikunda, S., Woo, J., Streets, D., Wei, C., Clarke, A., Huebert, B., and Anderson, T.: Impacts of dust on regional tropospheric chemistry during the ACE-Asia experiment: A model study with observations, J. Geophys. Res.-Atmos., 109, doi:10.1029/2003JD003806, D19S21, 2004.

Thulasiraman, S., O’Neill, N. T., Royer, A., Holben, B. N., Westphal, D. L., and McArthur, L. J. B.: Sunphotometric observations of the 2001 Asian dust storm over Canada and the US, Geophys. Res. Lett., 29, 1255, doi:10.1029/2001GL014188, 2002.

Tratt, D. M., Frouin, R. J., and Westphal, D. L.: April 1998 Asian dust event: A southern California perspective, J. Geophys. Res.Atmos., 106, 18371-18379, 2001.

Uno, I., Eguchi, K., Yumimoto, K., Liu, Z., Hara, Y., Sugimoto, N., Shimizu, A., and Takemura, T.: Large Asian dust layers continuously reached North America in April 2010, Atmos. Chem. Phys., 11, 7333-7341, doi:10.5194/acp-11-7333-2011, 2011.

Zhao, T. L., Gong, S. L., Zhang, X. Y., and Jaffe, D. A.: Asian dust storm influence on North American ambient PM levels: observational evidence and controlling factors, Atmos. Chem. Phys., 8, 2717-2728, doi:10.5194/acp-8-2717-2008, 2008. 